\title{
How do Sri Lankan University Libraries Employ Web 2.0 Tools in Providing Web-Based Library Services? : a Comparative Study
}

\author{
C.N.D. Punchihewa ${ }^{1}$
}

\begin{abstract}
Web 2.0 is a popular technology that creates new paths in communication, networking, building partnerships and resource sharing. Though Web 2.0 technology helps the libraries to employ innovative web-based services, fewer studies have been conducted to identify the utilization of Web 2.0 tools by Sri Lankan libraries. The aim of this paper is, to explore the types of Web 2.0 applications employed and to identify the purposes of embracing Web 2.0 applications in Sri Lankan university libraries. The Sri Lankan government university libraries which are under the University Grant Commission (UGC) of Sri Lanka were taken as the research population of this study and the total population was considered as the sample. Content analysis technique was adopted in this study for fifteen Sri Lankan government university libraries. The research instrument was a checklist consists of 60 checkpoints based on similar checklists found in the literature related to studies conducted on Web 2.0 applications and their usage. Data collection was conducted by accessing the web pages of these university library websites within a month period. Except for one university library, all the other fourteen university libraries introduced at least one Web 2.0 application with the primary features in their websites. Out of seven Web 2.0 tools considered in the study, Real Simple Syndication and Social Network Services are the most popular applications while Blogs, Vodcast and Podcast are less frequently used. Instant Messages and Wikis have not been implemented by any of them. Sri Lankan university libraries should be more focused on deploying Web 2.0 applications in their library websites to satisfy the needs of today's modernized user and also to be compatible with frequently changing technology.
\end{abstract}

Keywords : Library services, University libraries, Web 2.0, World Wide Web

\footnotetext{
${ }^{1}$ Senior Assistant Librarian, University of Moratuwa, Email: nishanp@uom.lk, (D) https://orcid.org/0000-0002-8261-8001
} 


\section{Introduction}

During the last two decades traditional environment of the library has rapidly transformed from a 'place-based' to a 'virtual' environment due to the introduction of Information Technology (IT) in libraries. Libraries need to face new objectives and challenges in information creation, promotion, distribution and storage with this advancement of technology. Developments in IT has forced the libraries to implement new library services, to modify the existing library services and also to shift towards new communication paradigms to cater to the modernized requirements of today's library user.

Improvements to library websites were begun during the 1990s as a new user-friendly communication method. According to Qutab and Mahmood (2009), academic health science libraries have started creating their own library websites with the release of the first web browser of the world 'Mosaic' in 1993. Except for a very few libraries, all the libraries in the world today, present their information through a library website to their patrons. However, the existence of a website does not assure the efficient use of the library and its services. As De Rosa et al. (as cited in Edda, 2014) have highlighted, usage of library websites in Canada and UK was reduced from $30 \%$ to $20 \%$ during 2005 to 2007 . In the same time period, a remarkable increase was observed among teenagers in the usage of search engines, email, and blogs. This situation has forced the libraries to change the contents and the structure of their websites to encourage user participation. As a result of this, dynamic interactive websites have been designed by replacing early static library websites.

Recognizing the needs of modernized library users, the majority of the libraries have integrated their library website with Web 2.0 technologies to enhance the interaction of the users towards the library. Librarians find many opportunities to provide different kinds of new services to their patrons at little or zero cost with the introduction of Web 2.0 tools on their websites. When Web 2.0 tools are implemented, many dynamic interactive channels are opened for both the librarians and the patrons to exchange, collaborate and generate the information. Web 2.0 tools have exposed a different path for the libraries to achieve their most important objectives that are information collection, information dissemination, information organization and information sharing. As information collection, organization, 
dissemination, and sharing are the main objectives of any library, Web 2.0 applications open a new path for them to achieve their most important expectations (Chua \& Goh, 2010).

\section{Literature Review}

According to Tripathi and Kumar (2010), Web 2.0 is a user-centered technology which leads to communicating and exchanging views or ideas. O'Reilly (2005) introduced the word Web 2.0 where he explains the users as a part of the websites. According to him, patrons act as creators and consumers of information. He has further explained Web 2.0 as "the business revolution in the computer industry caused by the move to the Internet as a platform and an attempt to understand the rules for success on that new platform". Coombs (2007) has described Web 2.0 as "a space that allows anyone to create and share information online; a space for collaboration, conversation, and interaction; a space that is highly dynamic, flexible and adaptable". As Chua and Goh (2010) have pointed out, Web 2.0 technology consists of server software, messaging protocols, content syndication, client applications and standard browsers.

As Harinarayana and Raju (2010) highlighted, today libraries have introduced various types of online services into their library websites such as two-way publishing sites (e.g.: Facebook), wikis, blogs, social bookmarking sites (e.g.: furl) and photo-sharing sites (e.g.: flicker). Also, Hanson and Cervone (as cited in Tripathi \& Kumar, 2010) have indicated that Wiki, blog, Really Simple Syndication (RSS), Instant Messaging (IM) and podcast as the main Web 2.0 applications used by academic libraries. On the other hand, Library 2.0 is the amalgamation of Web 2.0 expectations with web-based services of the library. Maness (2006) explained library 2.0 as "the application of interactive, collaborative and multimedia web-based technologies to web-based library services and collections".

Gamage (2009) has indicated the introduction of Web 2.0 tools in the websites of University Librarians Association (ULA), Sri Lanka Library Association (SLLA) and Special Libraries Association (SLA). He has clearly highlighted the importance and the advantages of introducing Web 2.0 technology in library websites. The usage of these websites have been 
steadily increasing after the implementation of different kinds of Web 2.0 tools on their library websites. Though the Web 2.0 features are heavily used by libraries in the world to provide communication facility, information sharing and collaboration, according to the Ranaweera and Li (2016), Web 2.0 features were one of the least used technologies in Sri Lankan university library websites.

As mentioned by Harinarayana and Raju (2010) many libraries have initiated to include various types of Web 2.0 tools on their websites to reach their patron population. Rogers (2015), Rehman and Shafique (2011), Chua and Goh (2010) and Han and Liu (2010) have explained how libraries have implemented Web 2.0 tools to initiate different library services.

\section{Real Simple Syndication (RSS)}

Real Simple Syndication is a popular Web 2.0 technology among many individuals. RSS could be explained as a collection of web feed formats which include regularly updated information in a standardized format (lightweight XML format). Dissemination of information is one the main objectives of any library in the world. RSS could be easily applied to support the information dissemination objective of libraries. Library users can use RSS to know the changes in the web without visiting the website. According to Linh (2008), RSS was the widely used Web 2.0 tool in Australian university libraries. As Chua and Goh (2010) and Rehman and Shafique (2011) have highlighted, RSS was mostly used to inform the news and events of the library, updates of the resources and services provided.

\section{Blog}

The blog is a frequently updated website with regular entries of comments, explanations, illustrations, and visuals. Generally, blogs are maintained by an individual or small group. Blogs allow to publish thoughts on the web and to obtain views from other web users. Chronologically arranged text, images, and media objects are included in blogs. Today, blogs have become one of the most popular forms of sharing ideas due to its reduced implementation cost and user-friendly features. The librarians could use blogs to disseminate information among users as it creates a real-time dialogue among the librarian and the users. Suggestions and feedback could be obtained directly 
from blogs (Chua \& Goh, 2010). As Han and Liu (2010) mentioned, informing the library events, promoting library resources, educating the staff and offering subjected related reference service are some of the benefits that could be obtained through blogs.

\section{Wiki}

Wiki is a website which is collaboratively developed by a community of users providing access to add and edit the content for any user. Chua and Goh (2010) as well as Rehman and Shafique (2011) have explained how the libraries have used a wiki in their library web pages. According to them, wikis could be used to create policy manuals, resource listings, subject guides and training resources.

\section{Social Networking Services (SNS)}

Information sharing is one of the main aspects of the library and its users. Social Networking Services are very popular applications that support information sharing that is one of the main objectives of libraries. As Han and Liu (2010) have explained in their study that top Chinese university libraries have utilized the SNS for publicizing library events, providing access to e-resources, offering online reference services and sharing photos. According to Chua and Goh, (2010), libraries have introduced SNS as an alternative channel to communicate with the users and also to build personalized connections with the library users. Facebook, Twitter, LinkedIn, and Myspace are some of the highly utilized free Social Networking Services used by libraries to communicate with the users, increase awareness on library resources and services through the features such as blogs, media sharing, tagging, and messaging provided in these SNS (Rogers, 2015; Chua \& Goh, 2010).

\section{Instant Messaging (IM)}

$\mathrm{IM}$ is a kind of Internet communication service that grants two parties to create a real-time online conversation using text-based messages. IM is another application that could be used to support the information sharing requirements of libraries. Libraries can use IM to create online reference services allowing the patrons to raise queries and obtain replies directly from the librarians in real time. Chua and Goh (2010) have highlighted that 
Yahoo-Instant Messenger, MSN Messenger, ICQ, and Skype are some of the common IM tools utilized by the libraries.

\section{Podcast}

A podcast consists of audio contents (music, news etc.) that could be downloaded directly to a computing device or portable media from the Internet. The term 'POD' stands for Portable On Demand and 'cast' is for broadcasting.

\section{Vidcast}

Vidcast could be explained as a video file designed to be viewed on a computer or portable media device downloading from the internet. This is also known as 'vodcast' or 'videocast' or 'vcast'.

\section{Research Objectives}

The objectives of this study were to;

i. Identify the types of Web 2.0 tools used in Sri Lankan university library websites

ii. Examine the purpose of using Web 2.0 tools by Sri Lankan university libraries

\section{Methodology}

Content analysis was the research method used in this study to collect data from library websites. As explained by Han and Liu (2010), content analysis was applied to recognize and verify the significance in different types of communication methodologies systematically and quantitatively. Today, content analysis is adopted to study the modern technologies such as radio, television, and websites (Han \& Liu, 2010; Linh, 2008). Krippendorf (1980) has highlighted some aspects of content analysis. These are listed as context sensitivity, the ability to accept unstructured materials, processing symbolic forms and the capability in dealing with large volumes of data. These characteristics and advantages were the reasons for selecting content analysis as the research method in this study.

There are fifteen (15) Sri Lankan government universities under the University Grant Commission (UGC) of Sri Lanka. All the library websites of these 15 universities were examined as the research sample to recognize 
the appearance of Web 2.0 tools and the purpose of using Web 2.0 tools. Table 1 displays the names of the selected university libraries.

Table 1. Surveyed university libraries

\begin{tabular}{|c|c|c|c|}
\hline University & Code & University & Code \\
\hline University of Colombo & $\mathrm{CMB}$ & $\begin{array}{l}\text { Eastern University of Sri } \\
\text { Lanka }\end{array}$ & EUSL \\
\hline University of Peradeniya & PDN & $\begin{array}{l}\text { South Eastern University } \\
\text { of Sri Lanka }\end{array}$ & SEUSL \\
\hline $\begin{array}{l}\text { University of Sri } \\
\text { Jayawardanapura }\end{array}$ & SJP & $\begin{array}{l}\text { Rajarata University of Sri } \\
\text { Lanka }\end{array}$ & RUSL \\
\hline University of Kelaniya & KLN & $\begin{array}{l}\text { Sabaragamuwa University } \\
\text { of Sri Lanka }\end{array}$ & SUSL \\
\hline University of Moratuwa & MRT & Uva Wellassa University & UWU \\
\hline University of Jaffna & UJF & $\begin{array}{l}\text { University of Visual \& } \\
\text { Performing Arts }\end{array}$ & UVPA \\
\hline University of Ruhuna & RUH & $\begin{array}{l}\text { The Open University of Sri } \\
\text { Lanka }\end{array}$ & OUSL \\
\hline
\end{tabular}

Wayamba University of Sri WUSL Lanka

Development of Research Instrument

Due to the absence of a comprehensive set of criterions for assessing Web 2.0 applications, a self-customized checklist was adopted to collect data as the research tool. The checklist was based on previous studies conducted by Han and Liu (2010), Tripathi and Kumar (2010) and Linh (2008) for identifying the purpose of applying Web 2.0 applications in library websites. The checklist contained checkpoints (questions) stating the existence or absenteeism of particular Web 2.0 tools and their utilization along with alternative answers $(\mathrm{Yes}=1, \mathrm{No}=0)$. The researcher was able to finalize 60 key points to explore the utilization of Web 2.0 tools available in Sri Lankan university libraries (Appendix I). 


\section{Data Collection}

The researcher accessed each library website separately and collected data regarding Web 2.0 tools according to the checklist. During one month period from $1^{\text {st }}-30^{\text {th }}$ September 2017 , data was collected. Following methods were applied to analyze the appearance of Web 2.0 applications in selected library websites.

- As Linh (2008) has mentioned in his study, library websites of all the government universities under the UGC of Sri Lanka were examined to identify the appearance of Web 2.0 tools such as RSS, blogs, IM, wikis etc. on their homepage or second level subpages.

- Also, the 'search' option for the websites was used to discover the availability of these web 2.0 applications in university library websites.

\section{Data Analysis and Results}

All the values obtained from each library website according to the checklist were entered in a Microsoft Excel Spreadsheet. Answers of each checkpoint were converted into values either 1 or $0(\mathrm{Yes}=1, \mathrm{No}=0)$. The overall weighting of each checkpoint was obtained to calculate the utilization of Web 2.0 technology in libraries.

Fourteen (14) university libraries out of fifteen surveyed libraries have included at least one type of Web 2.0 tool on their website to provide webbased services. None of the libraries have implemented all the Web 2.0 applications considered in the study and none of the libraries have included Instant Messaging (IM) applications and Wikis on their websites. As Linh (2008) and Tripathi and Kumar (2010) have explained, the following formula was applied to calculate the "Application Index" (AI) for each university.

\section{Application Index $(\mathrm{AI})=$ No of "Yes" checkpoints X 100 Total Check Points}

The level of usage of Web 2.0 technology in any library could be measured by calculating the application index of usage. A higher value for the application index indicates the higher implementation of Web 2.0 tools in libraries. Table 2 illustrates the application indices of the university libraries 
with regard to Web 2.0 applications. There is no single university library website that fulfilled all 60 items in the checklist. Sri Lankan university libraries have indicated a minimal usage of Web 2.0 tools in providing library services.

Table 2. Application index for the university library websites

\begin{tabular}{|c|c|c|c|c|}
\hline University & & AI & University & $\mathrm{AI}$ \\
\hline University of Colombo & & 8.33 & $\begin{array}{l}\text { Eastern University of Sri } \\
\text { Lanka }\end{array}$ & 8.33 \\
\hline University of Peradeniya & & 5.00 & $\begin{array}{l}\text { South Eastern University of } \\
\text { Sri Lanka }\end{array}$ & 8.33 \\
\hline $\begin{array}{l}\text { University of } \\
\text { Jayawardanapura }\end{array}$ & Sri & 11.67 & $\begin{array}{l}\text { Rajarata University of Sri } \\
\text { Lanka }\end{array}$ & 8.33 \\
\hline University of Kelaniya & & 10.00 & $\begin{array}{l}\text { Sabaragamuwa University } \\
\text { of Sri Lanka }\end{array}$ & 3.33 \\
\hline University of Moratuwa & & 28.33 & Uva Wellassa University & 11.67 \\
\hline University of Jaffna & & 5.00 & $\begin{array}{l}\text { University of Visual \& } \\
\text { Performing Arts }\end{array}$ & 13.33 \\
\hline University of Ruhuna & & 8.33 & $\begin{array}{l}\text { The Open University of Sri } \\
\text { Lanka }\end{array}$ & 5.00 \\
\hline
\end{tabular}

As Linh (2008) has explained, the mean of Web 2.0 application is determined by using the following equation.

$$
\begin{aligned}
\text { Mean Application Index } & =\frac{\text { Total of indexes }}{\text { Number of university libraries }} \\
& =135 / 15=9.0
\end{aligned}
$$

The mean of the Web 2.0 applications indices of Sri Lankan university libraries is 9.0. According to table 2, the library of the University of Moratuwa has the highest application index with 28 points and the library of the Sabaragamuwa University of Sri Lanka has the lowest application index. In comparison with the mean index, only four libraries have reached the 
mean index or above. One university library that failed to use any of the Web 2.0 application is not included in the table.

\section{Types of Web 2.0 Tools Used in Sri Lankan University Libraries}

Figure 2 shows, how different Web 2.0 applications have been employed in Sri Lankan university libraries. RSS, blogs, SNS, vodcast, and podcast are the main Web 2.0 tools adopted by the libraries. Wikis and IM are not implemented in any of the university library websites.

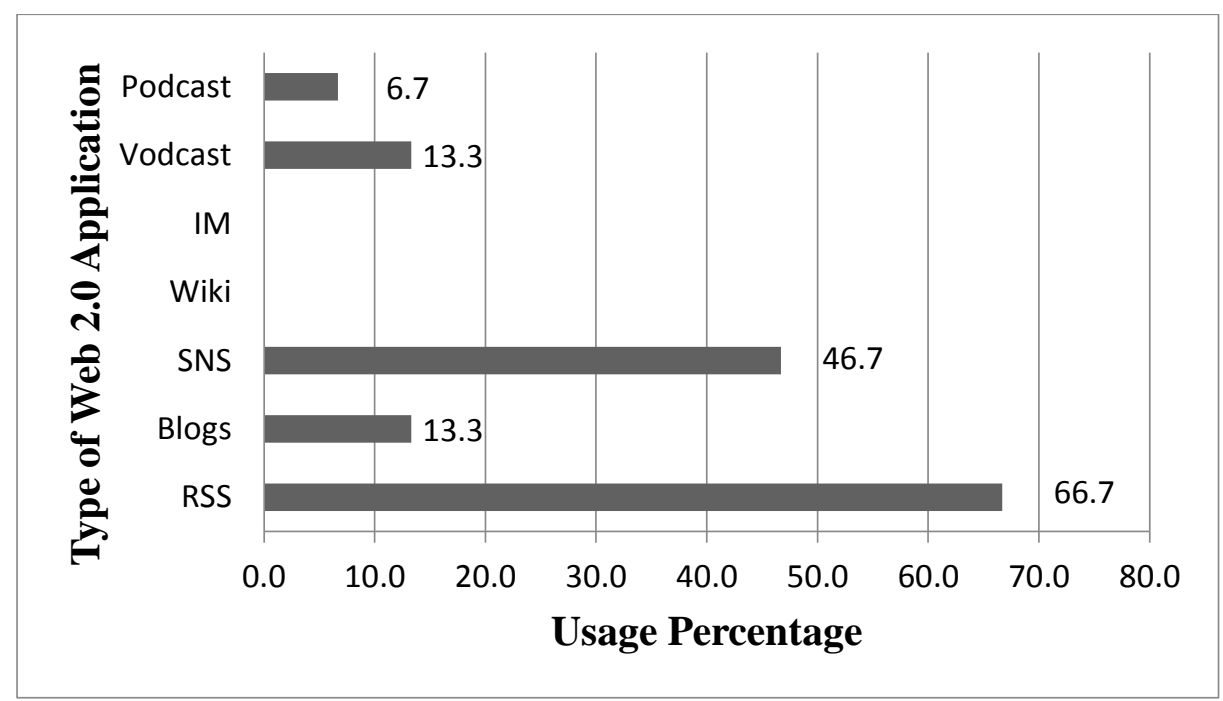

Figure 1. Utilization of Web 2.0 applications in Sri Lankan university libraries

Results of the study have revealed that RSS is the highly used Web 2.0 tool among Sri Lankan university libraries with the adoption rate of $66.7 \%$ (10 out of 14 libraries). The popularity of Web 2.0 technologies mainly depends on the simplicity, easy access capability and the minimum involvement of technical and human resources (Linh, 2008). RSS allows the users to easily subscribe to information that fulfills their needs.

Social Networking Services (SNS) show a $46.7 \%$ usage in university libraries (7 out of 15 libraries), becoming the second most implemented Web 2.0 tool. Blogs and vodcasts have the equal utilization measure with 13.3\% among the university libraries ( 2 out of 15 libraries) and podcast has the lowest usage $(6.7 \%)$. 
According to the survey results, Wikis and IM are not used by any of the Sri Lankan university libraries.

\section{Purpose of Using Web 2.0 Tools in Sri Lankan University Libraries}

Literature shows that RSS is mostly used by the libraries around the world to inform the news and events of the libraries and updates of resources and collections to their patrons. Linh (2008) has indicated that Australian libraries use RSS to introduce new books and new e-journals added to the library collection. According to the study conducted by Tripathi and Kumar (2010), the main purpose of using RSS by academic libraries in USA and the UK was providing general and university news and also the library news and events to the patrons. Same purposes have been highlighted by Han and Liu (2010) in their study for Chinese university libraries.

According to the results of the survey, Sri Lankan university libraries have not used RSS for different purposes. Though RSS has the highest usage percentage among university libraries, all the libraries use RSS for only one purpose. The libraries have used RSS to inform the patrons about the latest resources added to their digital libraries. All the university libraries which use RSS have created digital libraries by using D-space software. This software provides the facility to subscribe RSS as an additional feature. It was observed that all the Sri Lankan university libraries provide RSS in a basic level and most of the advantages of RSS tool has not been utilized properly. Further, none of the libraries have help or given instructions to the patrons on using RSS.

With the development of the technology, libraries should introduce an efficient and effective mechanism for the patrons to communicate with the library considering a medium that is already popular among the patrons. Today, various types of SNS are used by the university students and staff who are the main user groups of the university libraries. Therefore, libraries could easily implement SNS as a medium to exchange information between the library and its patrons.

Table 3 shows how Sri Lankan university libraries have utilized SNS for different purposes. They use SNS mainly for publicizing library events and news, introducing library facilities and service, informing the list of new books and periodicals to their patrons, providing library instructions, as a 
research tool and announcing workshops and exhibitions. Providing library news and events to their patrons through SNS is the most popular service (33.3\%) offered by university libraries.

Table 3 Purpose of SNS usage by Sri Lankan university libraries

\begin{tabular}{|c|c|c|}
\hline Purpose of using SNS & No of libraries & Percentage \\
\hline General or university news & 3 & 20.0 \\
\hline Library news and events & 5 & 33.3 \\
\hline List of new books & 2 & 13.3 \\
\hline $\begin{array}{l}\text { List of periodicals (print \& e-journals and e- } \\
\text { databases) }\end{array}$ & 2 & 13.3 \\
\hline Library facilities and services & 4 & 26.7 \\
\hline $\begin{array}{l}\text { Announcements about workshops and } \\
\text { exhibitions }\end{array}$ & 3 & 20.0 \\
\hline Help for catalogue search & 0 & 0.0 \\
\hline Library instructions & 1 & 6.7 \\
\hline Information literacy & 1 & 6.7 \\
\hline Research tool & 2 & 13.3 \\
\hline Instructions to use resources & 1 & 6.7 \\
\hline Instructions to use library facilities & 1 & 6.7 \\
\hline Library orientation tours & 1 & 6.7 \\
\hline
\end{tabular}

The libraries have established their own library SNS using various kind of popular social media sources. As Figure 2 illustrates, different types of SNS have been used by Sri Lankan university libraries to establish a communication channel with its patrons. All the libraries which use SNS have created their own library social network page by using one of the popular SNS or have provided a link to the university's SNS page. Facebook has become the most popular SNS among libraries while Twitter comes in at second. Generally, Facebook, Twitter, and Google+ have been utilized for providing information on library events, library news, library services and 
resources and also the university news. The library of the Eastern University of Sri Lanka has introduced Flicker SNS page to share photographs related to the library. YouTube is one of the main SNS applied by the University of Visual and Performing arts to visualize their creative works and the performances of the world. Though many universities have developed their own ResearchGate pages to support the research community of their university, the libraries of the University of Colombo and the Eastern University of Sri Lanka are the only libraries that have made the links from their library webpage to the university's ResearchGate page.

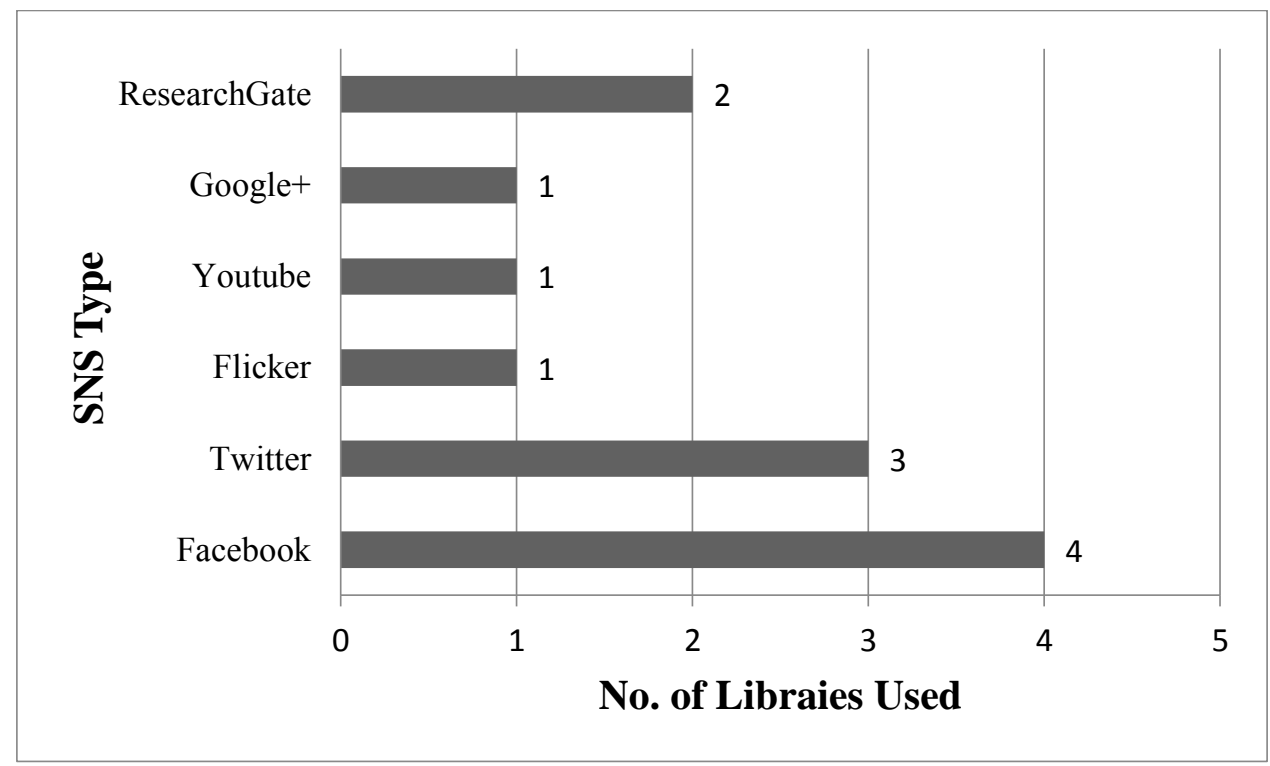

Figure 2: Types of SNS used by Sri Lankan university libraries

All libraries which use Web 2.0 applications have implemented only one type of social media except for two libraries. The library of the South Eastern University of Sri Lanka has offered links to three SNS which were created by the university. They have used Facebook, Twitter and Google ${ }^{+}$to provide the university news for their user community. Flicker and ResearchGate have been utilized by the library of the Eastern University of Sri Lanka.

Only two Sri Lankan university libraries have introduced the blog services to serve their library community. Promoting the library services and informing the library news and events are the main purposes of using blogs by the libraries of the University of Ruhuna and Uwa Wellassa University. 
Vodcast and podcast are rarely used by Sri Lankan university libraries, as they relate with sound and visuals. Only two libraries have included vodcast in their library websites such as the University of Moratuwa and the University of Visual and Performing Arts. The Library of the University of Moratuwa has introduced vodcast as a guidance video for its 'Library Orientation Tour' and also to provide instructions on how to use library resources. Publicizing the university events and offering subject related materials to the students are the main objectives of using vodcast by the University of Visual and Performing Arts. Same as the vodcast, the purpose of the podcast introduced by the University of Visual and Performing Arts is providing subject related materials for university students.

\section{Discussion}

Obtaining the advantages of Web 2.0 technology in Sri Lankan university libraries is still in the initial development stage compared to other libraries in the world. Most of the Sri Lankan university libraries use very few Web 2.0 applications in their websites to provide services and almost all the Web 2.0 tools used by the surveyed libraries are still extremely underdeveloped. Libraries have used only the basic features of most of the Web 2.0 applications other than the SNS. Though Sri Lankan university libraries have introduced at least one Web 2.0 application except for one library, it was observed that they have not utilized the maximum advantages of these Web 2.0 applications when offering the online services to their patrons. As Ranaweera and Li (2016) have pointed out, university libraries will be capable in facilitating modern, dynamic, high quality and attractive online library services with the introduction of properly customized Web 2.0 applications in their websites.

Literature shows that RSS has been used for many purposes by libraries around the world. Han and Liu (2010) have indicated three main objectives of using RSS by the libraries. The most popular intentions of using RSS are providing details on library news and events, new books or e-resources added to the collection and the university news to the patrons. The other purposes of applying RSS is, providing easy and timely access to categorized subject related information for their patrons. According to Han and Liu (2010), some Chinese university libraries have offered patrons' library usage 
records through RSS. But RSS tool is under-utilized among all the Sri Lankan university libraries. They have not even used RSS for informing library news and events which is the basic purpose of using RSS by the libraries around the world. All Sri Lankan university libraries which make use of RSS have provided RSS feed on the latest resources added to their digital libraries. However, these RSS feeds are in their basic stage and are not properly organized according to the subjects.

The blogs are another important Web 2.0 application that could be used to communicate a broad array of information. Blogs could be easily introduced to the library websites by using cheap or free software and requires a minimal maintenance effort. By using blogs, librarians get the opportunity to exchange ideas freely with their patrons. Basically, the main purpose of using blogs are for, informing library news and events to the patrons and introducing library services (Linh, 2008). Han and Liu (2010) further highlighted that blogs could be utilized to increase the awareness of library resources, train the patrons and offer online reference services. Communicating information on new books and e-resources added to the library collection and providing book reviews on popular titles are some of the additional services offered by the libraries by using blogs (Tripathi \& Kumar, 2010). Introducing the library services and communicating the library news and events are the only purposes of using blogs as observed in the two Sri Lankan university libraries. Similar to RSS, these blogs are also in their early stage and they should be customized in a useful manner to attract patrons.

Compared to the objectives of using other Web 2.0 tools, SNS is the highest utilized Web 2.0 tool by the Sri Lankan university libraries to offer many different services. As survey results revealed, seven university libraries use SNS to inform library events and news, publicize library facilities and services, create awareness on new books and e-resources, provide library instructions, as a research tool and announce workshops and exhibitions. Most of the libraries have created their own SNS page using Facebook, Twitter or Google ${ }^{+}$which are the most popular SNS among the Sri Lankan university libraries. However, the utilization of SNS such as Flicker, Youtube, and ResearchGate is minimal though they could be used to provide 
many new services. Libraries could create their own YouTube page to introduce a range of videos such as library orientation, instructions to use eresources and OPAC, library and university events, subject-related tutorials and some important lectures. On the other hand, libraries could use famous SNS like Flicker for sharing various kinds of photographs related to the library and the university. Providing support to improve the research culture of the university is one of the main aspects of any university library. ResearchGate is one the prominent SNS which is used to share scholarly information. Many universities have developed their own ResearchGate page comprising their research community. Only two Sri Lankan university library webpages provide access to their university ResearchGate page. Libraries could use this kind of scholarly SNS for promoting the sharing of research information and building a forum for the researchers to exchange their ideas

Both vodcast and podcast are mainly used for introducing searching techniques, providing instructions to find library resources, offering guidance to access the e-resources and online catalogue and conveying instructions to the patrons on using library facilities. Only two university libraries have implemented vodcast and podcast feeds in their library pages. For implementing podcast and vodcast services, libraries require sound recorders and related equipment with a suitable place. In addition, the library staff require special technical skills to produce and upload the sound and video files considering their downloading capability through the Internet. These reasons may have lead to the minimal usage of podcast and vodcast services in Sri Lankan university libraries. As mentioned by Linh (2008), libraries may extend their services through podcast especially for people with disabilities.

IM is a good technology for libraries to implement virtual reference services like 'Ask Librarian'. When employing this kind of virtual service with IM technology, librarians should always be online to help the patrons. Though the Sri Lankan university libraries have not implemented any IM services, there are many popular free IM services such as Yahoo Instant Messenger, MSN messenger and Skype. The lack of enough library members to offer this service on a full time basis, the skills of library staff in handling online 
queries in English and providing an undisturbed Internet facility may be the possible reasons for not using IM in university libraries

Wiki is another Web 2.0 application that is not utilized by any of the Sri Lankan university libraries. Academic libraries could use wikis for providing additional resources related to courses offered by the university according to the curricula. Linh (2008) has explained some reasons for not using Wikis in Australian university libraries. According to him, wiki spam is one of the main problems regarding the wikis as this contains unwanted links to commercial or pornographic sites. When creating, administrating and editing wikis, it creates many difficulties due to the lack of standards for wiki content markup.

\section{Conclusion}

Due to the advancement of technology and with the changes in user needs, libraries are anticipated to provide multilateral streams of information rather than their traditional static webpages. Recognizing these new requirements in the library environment, libraries have begun to introduce Web 2.0 applications in their website. Those web tools help the libraries to offer their services beyond the walls. According to Tripathi and Kumar (2010), Web 2.0 applications improve the relationship between the library and the patrons as they allow the patron to contribute to the library activities.

In this study, usage of seven common Web 2.0 tools in fifteen university libraries coming under the UGC of Sri Lanka were examined. The results of the study show that adoption of Web 2.0 tools in these government university libraries is quite low. Fourteen (14) university libraries out of fifteen use at least one type of Web 2.0 tool on their websites. IM and wikis are not used by any of the libraries and RSS is mostly used while SNS is the second widely used tool. Sri Lankan university libraries have adopted RSS for informing new resources added to their digital libraries and the main purpose of using blogs is to communicate the library news and events. SNS has been used to establish personalized relationships with the users while publicizing library events, facilities, and services. The main purpose of both vodcast and podcast are for offering guidance video for the 'Library Orientation Tour', providing instructions on using library resources and providing subject-related materials. 
Sri Lankan university libraries could implement many further steps to improve the usage of Web 2.0 applications in their library websites as Web 2.0 applications allow the libraries to introduce many new online services. As Web 2.0 technology is a new concept, librarians and the library staff should be educated to create awareness on various types of Web 2.0 applications and their advantages to the library. Following this practical workshops should be organized for the library staff to understand the importance of implementing Web 2.0 applications in their library websites. Also at the initial stage, students and the faculty staff should be trained to use various kind of Web 2.0 applications. Libraries could introduce a new practical session on Web 2.0 applications when they conduct user education programmes for the new students.

\section{References}

Chua, A. Y. K., \& Goh, D. H. (2010). A study of Web 2.0 applications in library websites. Library \& Information Science Research, 32(3), 203211. https://doi.org/10.1016/j.lisr.2010.01.002

Coombs, K. A. (2007). Building a library web site on the pillars of Web 2.0. Computer in Libraries, 27(1). Retrieved from http://www.infotoday.com/cilmag/jan07/Coombs.shtml

Edda, T. L. (2014). Integrating Web 2.0 into an academic library in Tanzania. The Electronic Library, 32(2), 183-202. https://doi.org/10.1108/EL-06-2012-0058

Gamage, R. (2009). Extended roles and responsibilities of library sssociation web sites. Journal of the University Librarians Association of Sri Lanka, 13(1), 47-60. https://doi.org/10.4038/jula.v13i1.1333

Han, Z., \& Liu, Y. Q. (2010). Web 2.0 applications in top Chinese university libraries. Library Hi Tech, 28(1), 41-62. https://doi.org/10.1108/07378831011026689

Harinarayana, N. S., \& Raju, N. V. (2010). Web 2.0 features in university library web sites. The Electronic Library, 28(1), 69-88. https://doi.org/10.1108/02640471011023388 
Krippendorf, K. (1980). Content analysis: An introduction to its methodology (3rd ed.). Beverly Hills: Sage Publications.

Linh, N. C. (2008). A survey of the application of Web 2.0 in Australasian university libraries. Library Hi Tech, 26(4), 630-653. https://doi.org/10.1108/07378830810920950

Maness, J. M. (2006). Library 2.0 theory: Web 2.0 and its Implications for libraries. Webology, 3(2). Retrieved from http://www.webology.org/2006/v3n2/a25.html

O'Reilly, T. (2005). What is Web 2.0: Design patterns and business models for the next generation of software. Retrieved from http://www.oreilly.com/pub/a/web2/archive/what-is-web-20.html

Qutab, S., \& Mahmood, K. (2009). Library web sites in Pakistan: An analysis of content. Program, 43(4), 430-445. https://doi.org/10.1108/00330330910998075

Ranaweera, A., \& Li, S. (2016). Web based library services of university libraries in Sri Lanka: A content analysis. In Proceedings of 8th Shanghai International Library Forum (SILF2016). Shanghai, China.

Rehman, A., \& Shafique, F. (2011). Use of Web 2.0 and its implications for libraries: Perceptions of information professionals in Pakistan. Library Philosophy and Practice. Retrieved from http://unllib.unl.edu/LPP/rehman-shafique.htm

Rogers, K. (2015). Academic and Public Libraries' Use of Web 2.0 Applications and Services in Mississippi. SLIS Connecting, 4(1), 33. https://doi.org/10.18785/slis.0401.08

Tripathi, M., \& Kumar, S. (2010). Use of Web 2.0 tools in academic libraries: A reconnaissance of the international landscape. The International Information \& Library Review, 42(3), 195-207. https://doi.org/10.1016/j.iilr.2010.07.005 


\section{Appendix I}

Checklist for exploring the adoption of Web 2.0 features in Sri Lankan University Libraries

Category 1: Use of Web 2.0

1. Does the library use any type of Web 2.0 technologies?

2. Does the library use RSS?

3. Does the library use blogs?

4. Does the library use SNS?

5. Does the library use wikis?

6. Does the library use IM?

7. Does the library use vodcast?

8. Does the library use podcast?

Category 2: Use of RSS

9. General or university news

10. Library news and events

11. List of new books

12. List of e-journals and e-resources databases

13. Announcements about workshops and exhibitions

14. Library facilities and services

15. Research information tool

Category 3: Use of Blogs

16. General information

17. Library news and events

18. Library services

19. List of new books

20. List of e-resources and databases

21. Guidance to use resources

22. Information literacy

23. Research tool 
Category 4: Use of Podcast

24. Library orientation tours

25 . Searching library catalogues

26. Guidance to use resources

27. Guidance to use library facilities

28. Information literacy tutorials

29. Library news

30. Subject related materials for students

31. General information

Category 5: Use of Vodcast

32. Library orientation tours

33. Guidance to use library facilities

34. Guidance to use e-resources

35. Guidance to access the catalogue

36. Subject related materials for students

37. General or university events

Category 6: Use of IM

38. Reference service

39. Advice on library services

40. Guidance to access resources

41. Others (upcoming events, trail access, lectures, etc.

Category 7: Use of Wiki

42. As subject guides

43. Project planning

44. Policy manuals

45. Listing of resources

46. Training materials

47. Others (referencing styles, plagiarism, etc.

Category 8: Use of SNS

48. General or university news

49. Library news and events

50. List of new books 
51. List of periodicals (print \& e-journals and e-databases)

52. Library facilities and services

53. Announcements about workshops and exhibitions

54. Help for catalog search

55. Library instructions

56. Information literacy

57. Research tool

58. Guidance to use resources

59. Guidance to use library facilities

60. Library orientation tours 